\title{
Synthesis and Characterization of Positive-Charge Functionalized Mesoporous Silica Nanoparticles for Oral Drug Delivery of an Anti-Inflammatory Drug**
}

\author{
By Chia-Hung Lee, Leu-Wei Lo, Chung-Yuan Mou,* and Chung-Shi Yang*
}

We synthesized mesoporous silica nanoparticles (MSN) with different densities of surface positive charges. The positive surface charge was generated by incorporating trimethylammonium (TA) functional groups into the framework of MSN (MSN-TA) via direct co-condensation of a TA-silane and tetraethoxysilane (TEOS) in the presence of a base as a catalyst. These MSN-TA samples have well-defined hexagonal structures with an average particle diameter of $100 \mathrm{~nm}$, pore size of $2.7 \mathrm{~nm}$, and surface area of about $1000 \mathrm{~m}^{2} \mathrm{~g}^{-1}$. Anionic drug molecules, Orange II (a fluorescent tracing molecule), and sulfasalazine (an anti-inflammatory prodrug used for bowel disease), were effectively loaded into these MSN-TA samples and remained inside of the MSNTA under acidic environment ( $\mathrm{pH} 2-5)$. The amounts of loading of both Orange II and sulfasalazine were increased with increasing positive charge densities resulting from the increasing number of TA groups. When these drug-loaded MSN-TA nanoparticles were placed in physiological buffer solution $(\mathrm{pH} 7.4)$, a partial negative surface charge on the MSN-TA was generated due to the deprotonation of silanol groups, and the strong electrostatic repulsion triggered a sustained release of the loaded molecules. MSN-TA as a nanovehicle for $\mathrm{pH}$-dependent loading and controllable release of anionic drug molecules can be used as an oral delivery drug systems targeting at intestine. These drugs can be remained trapped in the nanovehicle when passing through the stomach's acidic environment and be released in intestine where the environmental $\mathrm{pH}$ is close to neutral.

\section{Introduction}

Intelligent delivery of drugs often needs advanced design of functional materials. Organ-specific drug delivery system is an important aspect of pharmacotherapy. ${ }^{[1]}$ Colon-related diseases - such as irritable bowel syndrome, Crohn's disease, and

[*] Prof. C. S. Yang

Center for Nanomedicine Research

National Health Research Institutes

Zhunan, Miaoli 350 (Taiwan)

E-mail: cyang@nhri.org.tw

Prof. C. S. Yang

Department of Applied Chemistry and Graduate Institute of Biomedicine and Biomedical Technology

National Chi-Nan University, Puli, Nantou 545 (Taiwan)

Prof. C. Y. Mou

Department of Chemistry

National Taiwan University, Taipei 106 (Taiwan)

E-mail: cymou@ntu.edu.tw

Dr. C. H. Lee

Center for Nanomedicine Research

National Health Research Institutes Zhunan, Miaoli 350 (Taiwan)

Prof. L. W. Lo

Division of Medical Engineering Research

National Health Research Institutes Zhunan, Miaoli 350 (Taiwan)

[**] This work was supported by a grant from the National Health Research Institutes (NHRI-95-NM-PP-03) Taiwan, and a part of project grant from the National Science Council (NSC 95-2120-M002-009) of Taiwan. We thank Mr. Meng-Liang Lin for his assistance with the XRD measurement and Miss Yu-Ching Chen for her assistance with the TEM measurement. ulcerative colitis - could be more effectively treated when the therapeutic drugs are delivered to the colon tissue. ${ }^{[2]}$ To reduce the non-specific absorption along the delivery path and to deliver the active form of therapeutic drug to the lower section of the gastrointestinal tract (GI tract), oral drugs should be formulated to be acid resistant to first pass through the stomach and to reduce non-specific adsorption in upper section of the intestine before the drugs can effectively reach colon tissue. Although several approaches have been studied to deliver drugs to colon tissue, their efficiency in the delivery still encounters a lot of challenges. Our response to this challenge was to design a porous nanocarrier with a controlled-release function that decreased not only the degradation but also the non-specific release of drug molecules in the GI tract.

Mesoporous silica materials have generated vast interest ever since they were synthesized by Beck and co-workers in 1992. ${ }^{[3]}$ Because of the large surface area, large pore volume, highly ordered pore structure, and adjustable pore size, mesoporous silica material have wide and interesting applications in the fields of chemical catalysts ${ }^{[4]}$ and biotechnology. ${ }^{[5]}$ For example, mesoporous silica material can be used as a drug carrier for the controlled release of pre-loaded therapeutic drugs. ${ }^{[6]}$ Recently, mesoporous silica nanoparticles (MSN) has been synthesized using a two steps co-condensation process with cetyltrimethylammonium bromide (CTAB) as structure directing agent. Due to its nanosize, MSN has much higher cellular uptake efficiency than the micron-sized mesoporous silica particle ${ }^{[7]}$ thus therapeutic drugs or tracing molecules 
that are not easily membrane-transportable could be incorporated into the nanochannels of MSN to be delivered into cells. Another advantage of MSN is it can be suspended stably in solutions. The nanochannels of MSN have been loaded with anticancer drugs to be delivered into human cancer cells to induce cell apoptosis. The MSN can also incorporate high dosages of hydrophobic drugs inside the nanochannels of MSN. ${ }^{[8]}$ To increase the efficiency of MSN internalization into cells, MSN external surface may be modified with receptorspecific ligands (folic acid and lactobionic acid). The large internal surface area of MSN could carry toxic drug for therapeutic purpose. MSN can also incorporate contrast agent for in vivo cell-tracking purpose. ${ }^{[9]}$ Mesoporous silica has abundant silanol groups $(\mathrm{Si}-\mathrm{OH})$ on the pore surface, which facilitate their conjugation with different functional groups to increase the adsorption and conjugation of relevant biological molecules. ${ }^{[10]}$ Several research groups have studied the sustained-release properties of drugs loaded in conventional mesoporous silica microsized particles (i.e., MCM-41, MCM-48, and SBA-15). ${ }^{[1]}$ Vallet-Regi and co-workers ${ }^{[12]}$ used aminopropyl groups modified MCM-41 with different pore sizes to regulate the release rate of ibuprofen from the siliceous matrix. Stucky and co-workers ${ }^{[13]}$ also indicated that the anionic proteins could be adsorbed in the nanochannels of aminopropyl group-modified mesoporous silica, and then released by changing the environmental ionic strength. In addition to amine-modified mesoporous silica, hollow mesoporous silica (HMS) nanospheres with pore channels penetrating from the outside to the inner hollow core can store significantly more aspirin molecules than conventional mesoporous silica. ${ }^{[14]}$ Besides the sustained and spontaneous release system, a stimuli-responsive release system has been designed, for example, a cap formed by disulfide bond can be opened by cleavage of the disulfide bond with reducing agent to trigger the release of the entrapped molecules. ${ }^{[15,16]}$ Xiao et al. designed a $\mathrm{pH}$ stimuli-responsive controlledrelease system composed of oppositely charged ionic interaction between carboxylatemodified SBA-15 and cationic polyelectrolyte. When the solution condition is of mild acidity, the caps (polyelectrolyte) on the channel opening dissolve and cause loaded vancomycin to steadily release from the pores of SBA-15. ${ }^{[17]}$

Drug loading efficiency usually relies on the affinity between the nanocarrier and the drug molecules. When a drug molecule is loaded inside of the non-functionalized silica matrix through a weak attraction (i.e., hydrogen bonding), a low loading capacity and a fast releasing profile are usually observed. For charge carrying drug molecules, we propose to increase the drug-loading efficiency by strengthening the electrostatic attraction through a modification of the mesoporous silica material's surface to bear more opposite charges.

In this paper, we report a synthesis of positively charged MSN by co-condensation of TA-silane and tetraethoxysilane (TEOS) under basic conditions. The high positive charge density of TA groups generated a strong electrostatic attraction between the surface of MSN and the negative (acidic) groups of the drug molecules. Sulfasalazine and Orange II were employed as loading compounds to examine the capability of controlled release in simulated gastric fluid $(\mathrm{pH}$ 1.2) and intestinal fluid $(\mathrm{pH}$ 7.4). The effects of TA concentrations, loading concentrations, and solution $\mathrm{pH}$ on the loading efficiency were investigated. As shown in Scheme 1, an anionic drug molecule is adsorbed inside of the nanochannels of the MSN-TA through electrostatic attraction in an acidic solution and then the molecules can be released by increasing either the $\mathrm{pH}$ value (to $\mathrm{pH}$ 7.4) or ionic strength. The $\mathrm{pH}$ triggered release is mainly due to the change of the surface charges in MSN-TA sample (MSN-TA carry positive charges in acidic $\mathrm{pH}$ and negative charges in neutral condition), the negative charges of drug molecules could have strong attraction when placed with MSN-TA in a weak acid solution and have strong repulsion (spontaneous and sustained release) when the $\mathrm{pH}$ of the solution was changed to be neutral. This vehicle can be used for the delivery of prodrug (sulfasalazine) into the colon. The $\mathrm{pH}$-triggered release of mechanism from
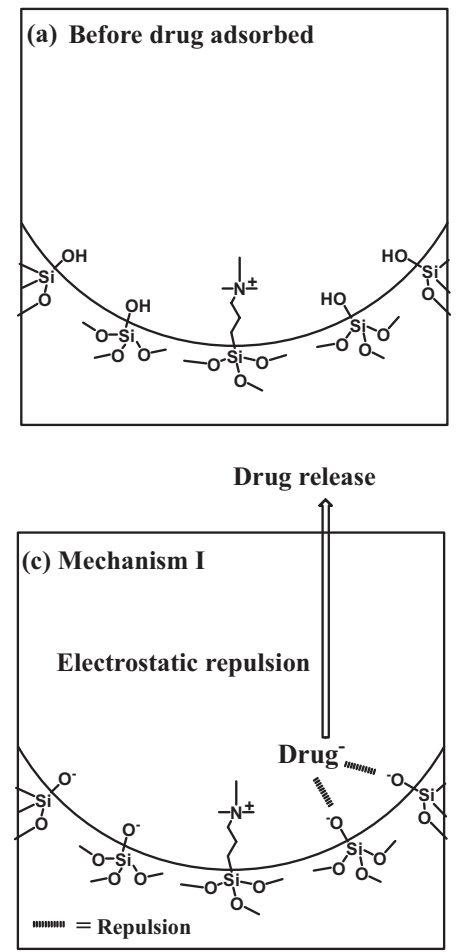

Scheme 1. The representation of the sustained-release mechanism of an anionic drug adsorbed in MSN-TA sample. a) Before drug adsorbed, b) after drug adsorbed, c) drug released by electrostatic repulsion under neutral $\mathrm{pH}$, and $\mathrm{d}$ ) drug released by increasing the ionic strength. 
drug loaded MSN-TA samples demonstrated their potential to be used in tissue specific delivery systems for oral drug administration.

\section{Results and Discussion}

\subsection{TEM}

The transmission electron microscopy (TEM) images of MSN-TA samples are shown in Figure 1. The MSN-TA samples are of hexagonal shape and uniform size, with the average particle diameter about $100 \mathrm{~nm}$ (Fig. 1). Conjugation of TA functional groups onto the MSN samples did not appear to affect the MSN's size (data not shown). These results indicated that the different density of the organic functional groups in MSN can be easily controlled and optimized by the sol-gel co-condensation process.

\subsection{Powder XRD}

X-ray diffraction (XRD) patterns of the MSN-TA samples are shown in Figure 2. All the samples exhibit a hexagonal mesoporous structure, which is typical of MCM-41 type with (100), (110), and (200) reflections of P6mm symmetry. ${ }^{[18]}$ With the increasing amounts of TA groups in the MSN-TA, the XRD patterns showed gradual broadening, indicating a decrease in the order of the structure and suggesting the conjugation with increasing numbers of TA functional groups had changed the MSN pore structure from 2-D hexagonal ordered pores to wormlike pores. In our experiments, the optimum condition was $2-12 \% \mathrm{v} / \mathrm{v}$ of TA-silane, which resulted in an ordered pore structure, large surface area, suitable positive charge, and the defined size.

\subsection{FTIR Spectra}

We employed IR spectra to study the organic side groups' presence in the framework of MSN. The IR spectrum of $\mathrm{HCl}$ extracted MSN without TA-modification (P-MSN) is shown in Figure 3a. Before extraction, the large amount of surfactant present in the sample gave the characteristic $\mathrm{C}-\mathrm{H}$ valence
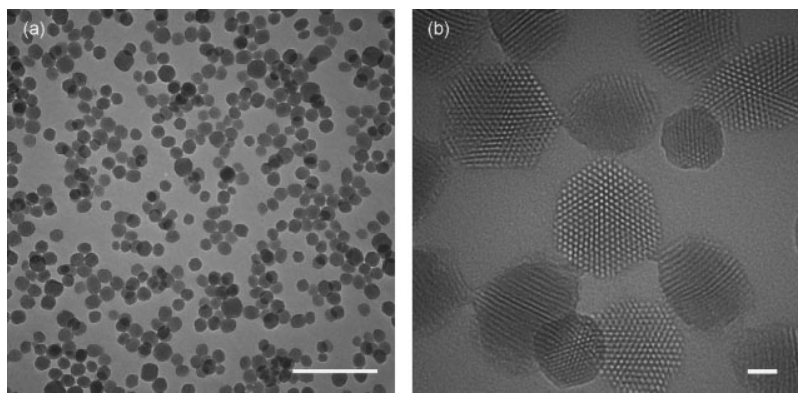

Figure 1. TEM micrographs of the TA groups functionalized MSNs (MSNTA). Scale bars: a) $500 \mathrm{~nm}$ and b) $20 \mathrm{~nm}$. The structure of nanochannels was revealed as hexagonal arrangement.

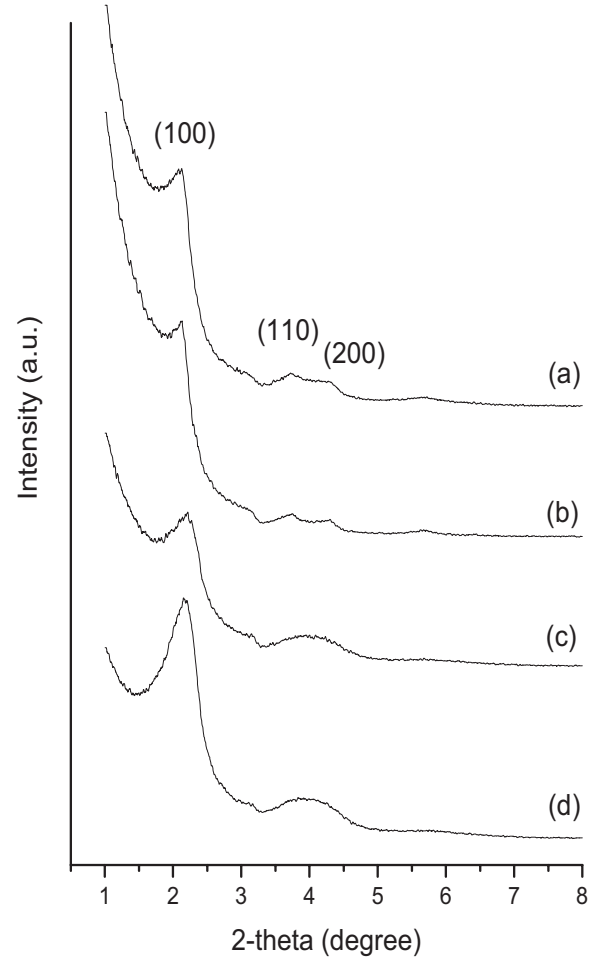

Figure 2. X-Ray powder diffraction spectra of a) MSN-TA-1, b) MSN-TA-2, c) MSN-TA-3, and d) MSN-TA-4 samples.

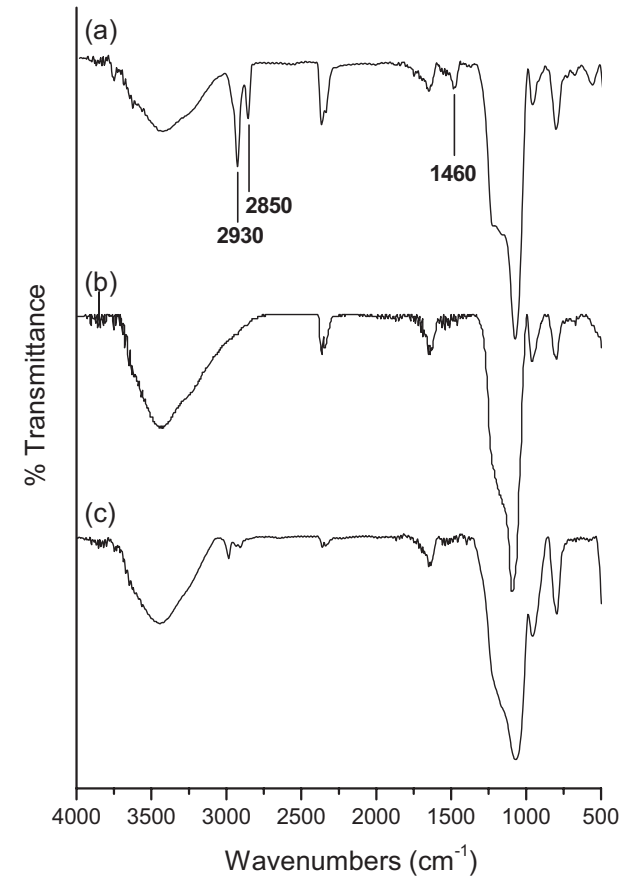

Figure 3. FTIR spectra of a) P-MSN before extraction, b) P-MSN after extraction in a $\mathrm{HCl}-\mathrm{EtOH}$ solution for 1 day, and c) MSN-TA-4 after extraction in a $\mathrm{HCl}-\mathrm{EtOH}$ solution for 1 day. 
bands at $2850-2930 \mathrm{~cm}^{-1}$ and $\mathrm{C}-\mathrm{H}$ deformation bands around $1460 \mathrm{~cm}^{-1}$ due to the surfactant (CTAB) molecules. ${ }^{[19]}$ After extraction, the complete removal of the surfactant was confirmed by the fact that these $v(\mathrm{C}-\mathrm{H})$ peaks from the CTAB molecules all disappeared (Fig. 3b). However, the TA modified MSN (MSN-TA-4) showed the presence of $v(\mathrm{C}-\mathrm{H})$ mode at 2850-2930 $\mathrm{cm}^{-1}$ after $\mathrm{HCl}-\mathrm{EtOH}$ extraction (Fig. 3c). The results indicated that the TA groups were indeed modified in the framework of MSN by covalent bonding in the one step sol-gel process.

\subsection{Nitrogen Adsorption Studies}

Nitrogen adsorption-desorption isotherms and pore-size distribution of MSN before and after the loading of Orange II

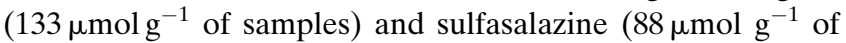
samples) are shown in Figure 4. The amounts of nitrogen adsorbed decreased with increasing amounts of loading molecules (data not shown), mainly because the channels were occupied by the dye/drug molecules, which left less space for nitrogen adsorption. The pore size of MSN-TA-3 decreased from 27 to $22 \AA$ (when loaded with Orange II) and $24 \AA$ (when loaded with sulfasalazine), the pore volume decreased from 1.000 to 0.505 and $0.628 \mathrm{~cm}^{3} \mathrm{~g}^{-1}$. The surface area was reduced from 1033 to 690 and $707 \mathrm{~m}^{2} \mathrm{~g}^{-1}$ after being loaded with Orange II and sulfasalazine, respectively (Table 1). A portion of decrease in the surface area and pore volume, as well as a shift of the average pore size from 27 to 22 and $24 \AA$, indicated that the dye/drug molecules inside the nanochannels only partially occupy the pore space, so that there was still some room for $\mathrm{N}_{2}$ adsorption. These results also provided additional evidence that the dye/drug molecules were indeed adsorbed in the nanochannels of MSN-TA samples.

\subsection{Zeta-Potential Analysis}

We measured the $\zeta$-potential of P-MSN and MSN-TA samples in solutions with the $\mathrm{pH}$ ranging from 2 to 8 by automatic titration (Fig. 5). At pH 2.0, all the MSN samples showed the positive $\zeta$-potential values, either when being conjugated with TA groups (MSN-TA-1, +30.3; TA-2, +32.1; TA-3, +33.7 ; TA- $4,+39.4 \mathrm{mV}$ ) or without TA groups (P-MSN: $+2.0 \mathrm{mV})$. We observed that the positive charge densities (from $\zeta$-potential measurements) were directly related to the

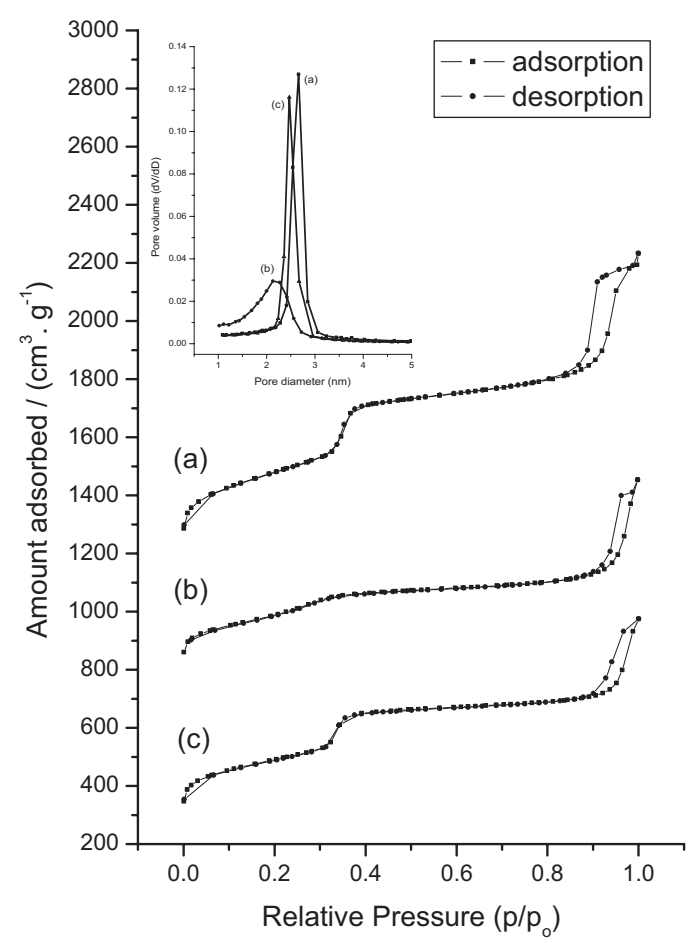

Figure 4. a) Nitrogen adsorption-desorption isotherms and pore size distribution of MSN-TA-3 sample (a) without loading molecule, b) after Orange II $\left(133 \mu \mathrm{mol} \mathrm{g}^{-1}\right)$, and c) after sulfasalazine $\left(88 \mu \mathrm{mol} \mathrm{g}^{-1}\right)$ adsorbed.

number of TA groups on the MSN samples. This phenomenon provided additional evidence that different TA densities were indeed modified in the framework of MSN by the sol-gel process. When the $\mathrm{pH}$ was raised to 7.4 , the silanol groups on the surface became deprotonated, and thus all of the MSN samples thus exhibited negative $\zeta$-potential values (P-MSN, -40.6; MSN-TA-1, -35.1; TA-2, -28.8; TA-3, -22.2; TA-4, $-11.7 \mathrm{mV})$. These results suggested that we could manipulate the TA (positive) density in the framework of MSN to optimize the loading capacity. Negatively charged drug molecules were loaded into MSN when solution was under acidic condition ( $\mathrm{pH} 4-6$ ) since the MSN surface was covered by partial positive charges. When the solution $\mathrm{pH}$ was increased to 7.4 , a strong electrostatic repulsion was generated between the surface of MSN and the negative dye/drug molecules, which triggered

Table 1. Surface area, pore size, pore volume, and adsorbed amounts of P-MSN and MSN-TAs.

\begin{tabular}{|c|c|c|c|c|c|c|c|}
\hline \multirow[t]{2}{*}{ Sample } & \multirow{2}{*}{$\begin{array}{c}\text { TA-silane } \\
\text { added }[\mu \mathrm{L}] \\
\text { per } \mathrm{mL} \text { of } \mathrm{EtOH}\end{array}$} & \multirow[t]{2}{*}{$\begin{array}{l}\text { Surface area } \\
\qquad\left[\mathrm{m}^{2} \mathrm{~g}^{-1}\right]\end{array}$} & \multirow[t]{2}{*}{$\begin{array}{c}\text { Pore } \\
\text { size }[\AA]\end{array}$} & \multirow[t]{2}{*}{$\begin{array}{l}\text { Pore volume } \\
{\left[\mathrm{cm}^{3} \mathrm{~g}^{-1}\right]}\end{array}$} & \multirow{2}{*}{$\begin{array}{l}\text { Orange II } \\
\text { adsorbed } \\
{\left[\mu \mathrm{mol} \mathrm{g}{ }^{-1}\right]}\end{array}$} & \multicolumn{2}{|c|}{$\begin{array}{c}\text { Sulfasalazine adsorbed } \\
{\left[\mu \mathrm{mol} \mathrm{g}{ }^{-1}\right]}\end{array}$} \\
\hline & & & & & & $\mathrm{H}_{2} \mathrm{O}[\mathrm{a}]$ & DMSO $[\mathrm{b}]$ \\
\hline P-MSN & 0 & 1022 & 27 & 0.969 & 17.4 & 0.5 & 4.7 \\
\hline MSN-TA- 1 & 20 & 1004 & 27 & 0.967 & 70.9 & 10.1 & 59.6 \\
\hline MSN-TA-2 & 50 & 1081 & 27 & 1.027 & 99.6 & 20.7 & 74.2 \\
\hline MSN-TA-3 & 80 & 1033 & 27 & 1.000 & 132.9 & 28.2 & 87.5 \\
\hline MSN-TA-4 & 120 & 1026 & 27 & 0.968 & 167.8 & 42.8 & 103.1 \\
\hline
\end{tabular}

[a]Sulfasalazine was adsorbed from aqueous solution. [b]Sulfasalazine was adsorbed from DMSO solution. 


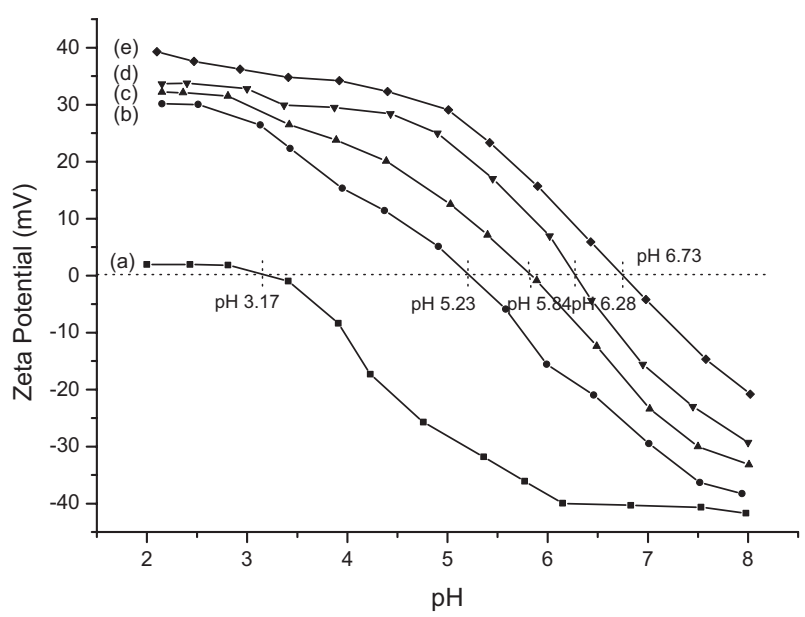

Figure 5. Zeta potential of a) P-MSN, b) MSN-TA-1, c) MSN-TA-2, d) MSN-TA-3, and e) MSN-TA-4 at different $\mathrm{pH}$. The $\mathrm{pH}$ value of point of zero charge (PZC) for P-MSN: 3.17; MSN-TA-1: 5.23; MSN-TA-2: 5.84; MSN-TA-3:6.28; and MSN-TA-4: 6.73 .

their $\mathrm{pH}$-dependent release. In addition, the increased number of TA groups also increased the $\mathrm{pH}$ values for the MSN samples to reach the point of zero charge (PZC) (P-MSN, 3.17; MSN-TA-1, 5.23; TA-2, 5.84; TA-3, 6.28; TA-4, 6.73). The $\mathrm{pH}$ values for PZC marked the onset of release for drugs loaded in the MSN-TA samples. When the $\mathrm{pH}$ value was high than PZC, the drugs can be released in a sustained manner. Usually the $\mathrm{pH}$ increased from the stomach ( $\mathrm{pH} 1.0-3.0)$, to small intestine ( $\mathrm{pH}$ 6.5-7.0), and finally to the colon ( $\mathrm{pH} 7.0-8.0$ ), therefore the different PZC of the MSN-TA samples can thus allow the association and dissociation of loaded drugs depending on the different $\mathrm{pH}$ values in the GI tract.

\subsection{Effects of Dye/Drug Concentrations on the Adsorption Efficiency}

The effects of various initial dye/drug concentrations (Orange II: $0.25,0.75,1.25,1.75,2.25$, and $2.75 \mathrm{~mm}$; and sulfasalazine: $10,15,31,45,58$, and $75 \mu \mathrm{M}$ ) on their loading efficiency to P-MSN and MSN-TA with different TA densities [P-MSN (0\%), MSN-TA-1 (2\%), TA-2 (5\%), TA-3 (8\%), TA-4 (12\%) (v/v)] were investigated. The adsorption profiles for Orange II adsorbed onto the five MSN samples were shown in Figure 6. A general pattern was observed for all four MSNTA samples: the amounts of Orange II molecules adsorbed onto the MSN-TAs were increased with the increasing Orange II concentrations. This is probably due to the higher concentrations of Orange II generated a stronger gradient to facilitate the diffusion of Orange II molecules into the MSN nanochannels. It is interesting to note that the MSN-TA-2, -3, and -4 samples had very similar adsorption capacities at a low concentration of Orange II solution $(0.25 \mathrm{~mm})$, suggesting these three types of MSN-TAs have more positively charged (TA) groups than the entering Orange II molecules and that therefore this adsorption was predominantly diffusion depen-

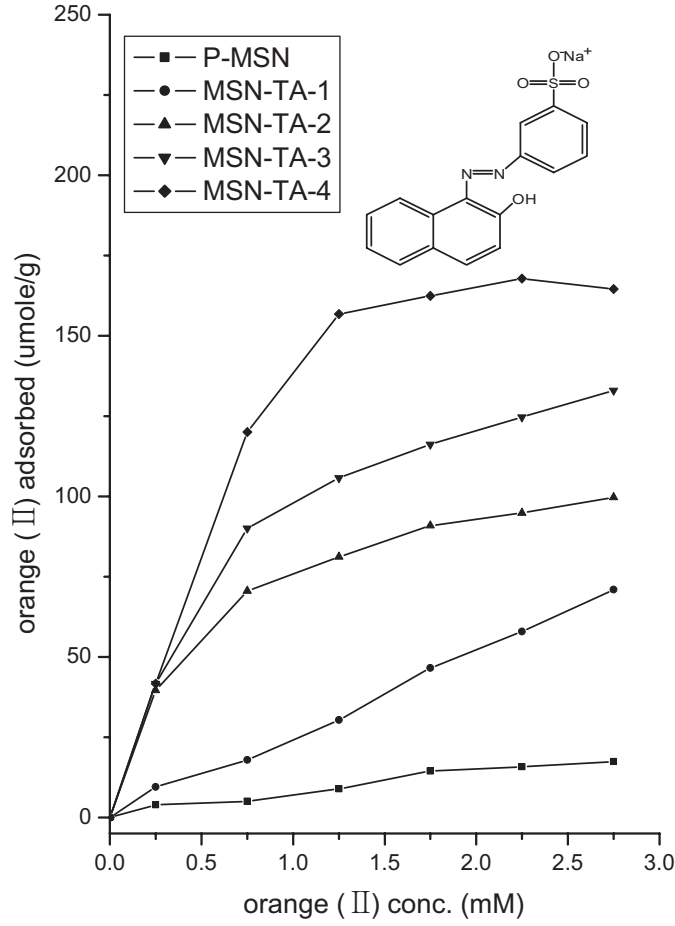

Figure 6. Adsorption at $300 \mathrm{~K}$ and $\mathrm{pH} 6.8$ of Orange II on (ם) P-MSN

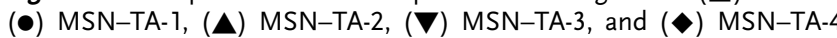
samples at various solution concentrations.

dent. At higher Orange II concentrations $(0.75-2.25 \mathrm{~mm})$, the amounts of Orange II adsorbed onto MSN-TA were increased with the increasing TA densities (the amounts loaded were MSN-TA-4 $>$ MSN-TA-3 $>$ MSN-TA-2 $>$ MSN-TA-1 $>$ P-MSN), suggesting the number of Orange II molecules were in excess of the positively charged molecules in the nanochannels and thus a surface charge density-dependent adsorption profile was observed. The maximum adsorption of P-MSN, MSN-TA-1, -2, -3, and -4 samples in Orange II solution was $17.4,70.9,99.6,132.9$, and $167.8 \mu \mathrm{mol} \mathrm{g}{ }^{-1}$, respectively, following the order of increasing TA (Table 1). A low loading of Orange II in P-MSN sample may have come from the higher electrostatic repulsion between the host and the guest at $\mathrm{pH} 6.8(\zeta$-potential: $-40.3 \mathrm{mV})$. In previous experiments of nitrogen adsorption-desorption isotherms, the MSN-TA samples showed a decrease of $33 \%$ in surface area, $50 \%$ in pore volume, and $5 \AA$ in pore size at the saturated adsorption. The decreases in these three parameters indicated that the channels were not fully occupied.

Figure 7 showed the adsorption curves of sulfasalazine onto P-MSN and MSN-TAs samples at different concentrations. The adsorbent profile that was similar to that of Orange II, and the loading of sulfasalazine molecules was enhanced with increasing sulfasalazine concentrations. In addition, MSN-TA-3 and -4 samples also showed the diffusion-dependent adsorption of sulfasalazine molecules at low concentration $(10-15 \mu \mathrm{M})$. A similar surface charge density-dependent adsorption behavior at higher concentrations was observed. The maximum adsorption of P-MSN, MSN-TA-1, -2, -3, and 


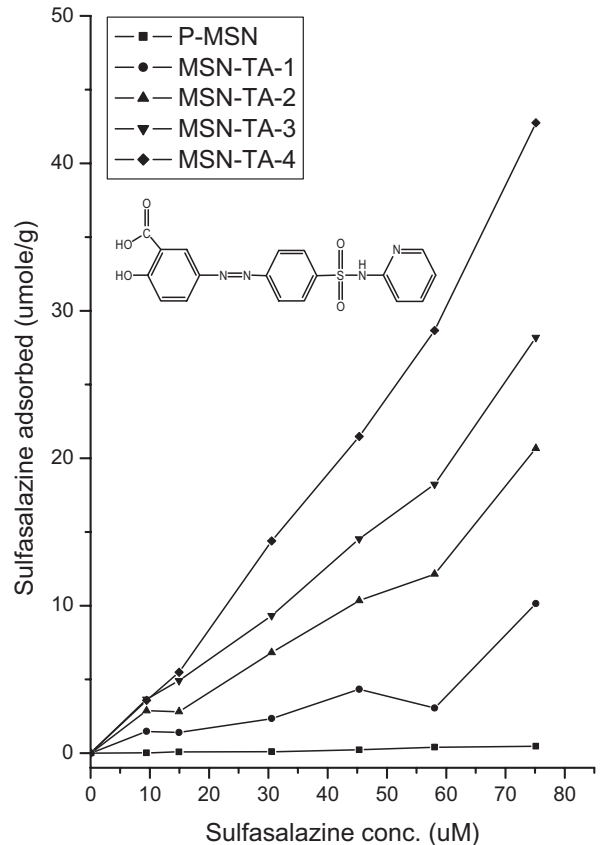

Figure 7. Adsorption at $300 \mathrm{~K}$ and $\mathrm{pH} 5.4$ of sulfasalazine on (口) P-MSN,

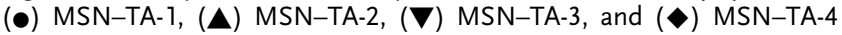
samples at various solution concentrations.

-4 samples in sulfasalazine $/ \mathrm{H}_{2} \mathrm{O}$ solution was $0.5,10.1,20.7,28.2$, and $42.8 \mu \mathrm{mol} \mathrm{g}^{-1}$, respectively (Table 1 ). We observed that the maximum adsorption for sulfasalazine was lower than of Orange II. The low loading efficiency may be because sulfasalazine is a more hydrophobic molecule and shows less attraction to the hydrophilic nanochannels. In addition, the P-MSN sample showed not only the hydrophilic character but a low $\zeta$-potential at $\mathrm{pH} 5.4$ ( $\zeta$-potential: $-32.5 \mathrm{mV}$ ) so the strong electrostatic repulsion caused a very low loading efficiency. To increase the loading of sulfasalazine, we loaded sulfasalazine into MSN from a DMSO solution. The higher concentration would more strongly promote the sulfasalazine to diffuse and enter the hydrophilic nanochannels of MSN. The maximum adsorption of P-MSN, MSN-TA-1, $-2,-3$, and -4 samples in sulfasalazine/ DMSO solution was 4.7, 59.6, 74.2, 87.5, and $103.1 \mu \mathrm{mol} \mathrm{g}^{-1}$, respectively (Table 1 ). Indeed, the loading is higher compared to loading from aqueous solution.

\subsection{Effect of $\mathrm{pH}$ on Dye/Drug Adsorption}

Effects of environmental $\mathrm{pH}$ (from 1 to 10) on the adsorbed amounts of Orange II and sulfasalazine molecules onto MSNTA-4 sample are investigated and the results are shown in Figure 8. Orange II and sulfasalazine have high loading efficiency in the $\mathrm{pH}$ range from 2 to 5 . Because the $\mathrm{pH}$ value of PZC in MSN-TA-4 sample was 6.73, the $\zeta$-potential showed highly positive charge in the $\mathrm{pH}$ range from $2(+39.4 \mathrm{mV})$ to 5 $(+29.2 \mathrm{mV})$. The high loading ability in this $\mathrm{pH}$ range was due to the strong electrostatic attraction. Besides, a slight decrease

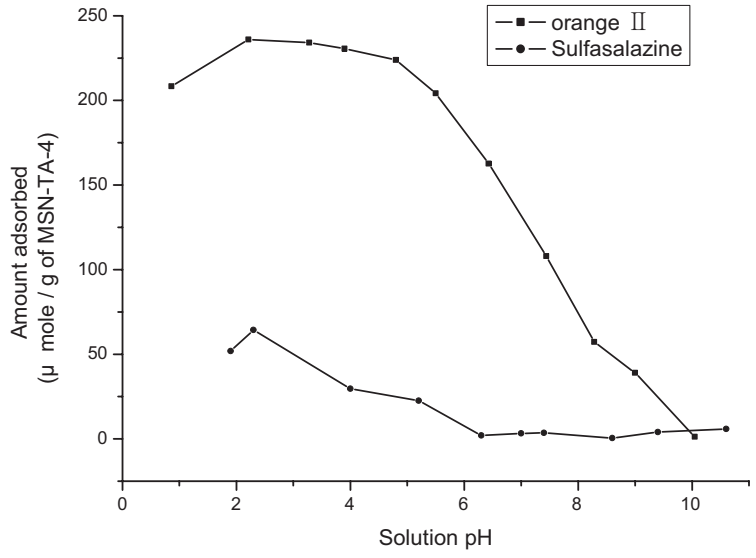

Figure 8. Adsorption at $300 \mathrm{~K}$ of Orange II $(1.25 \mathrm{~mm})(\boldsymbol{\square})$ and sulfasalazine $(30.6 \mu \mathrm{M})(\bullet)$ on MSN-TA-4 samples at various $\mathrm{pH}$ values.

in the loading capability at lower $\mathrm{pH}$ values $(\mathrm{pH} \leq 1.0)$ was resulting from the protonation of the acidic groups in the dye/ drug molecules $\left(-\mathrm{SO}_{3}{ }^{-}\right.$to $-\mathrm{SO}_{3} \mathrm{H}$ or $-\mathrm{COO}^{-}$to $\left.-\mathrm{COOH}\right)$. Once the functional groups were protonated, the electrostatic attraction between the TA groups and the dye/drug molecules would decrease and cause the low loading efficiency. The decrease in the loading capability from $\mathrm{pH} 6$ to 10 was resulted from the presence of unmodified silanol ( $\mathrm{Si}-\mathrm{OH})$ groups on the surface of the MSN-TA sample. The silanol groups underwent deprotonation at high $\mathrm{pH}$ value. The negative charges of $-\mathrm{Si}-\mathrm{O}^{-}$groups in the MSN-TA surface were produced, therefore the $\zeta$-potential was decrease from $+13.3 \mathrm{mV}(\mathrm{pH}$ 6.0) to $-38.0 \mathrm{mV}(\mathrm{pH} \mathrm{10)}$. The strong negative repulsion between the surface of MSN and the loaded molecules caused a decreasing adsorption in this $\mathrm{pH}$ range.

\subsection{Effects of the TA-Groups Density on the Release Rate}

The major colonic drug-delivery systems developed during the past decade are based on formulation for time-dependent release, ${ }^{[20]} \mathrm{pH}$-sensitive polymer coatings, ${ }^{[21]}$ and prodrug systems, ${ }^{[22]}$ respectively. Formulation for time-dependent release is designed to delay the onset of drug release until the formulated drugs have reached the colon tissues; the precise control of this colon-specific release is not easily achieved due to variations in how long the formulated drugs may stay in the stomach and small intestine. The $\mathrm{pH}$ dependent release systems is based on the different $\mathrm{pH}$ values in various parts of the GI tract, which increases from the stomach ( $\mathrm{pH} 1.0-3.0)$, to the small intestine ( $\mathrm{pH}$ 6.5-7.0), and to the colon $(\mathrm{pH} 7.0-8.0) ;{ }^{[23]}$ although successful passage through stomach can be expected, this design may result in an early release in the small intestine due to the insignificant $\mathrm{pH}$ variation between the small intestine and colon. Finally, the prodrug strategy has the advantage of producing the active drug molecules by bacteria-catalyzed reaction in the colon 
(about $10^{12} \mathrm{CFU} / \mathrm{mL}$ ); the existence of bacteria (about $\left.10^{4} \mathrm{CFU} / \mathrm{mL}\right)^{[24]}$ in the stomach and small intestine, however, may lead to the production of active drug molecules in places other than the colon. Therefore, in the current study we designed a nanodelivery vehicle to combine the two advantages of $\mathrm{pH}$-dependent release and prodrug systems. For the prodrug compound, we chose a commercially available prodrug, sulfasalazine, which can be cleaved by colonic bacteria (Azoreductases) to yield 5-aminosalicylic acid (5-ASA), which acts as an active moiety in the treatment of two major human chronic inflammatory bowel diseases (Crohn's disease and ulcerative colitis). ${ }^{[25]}$

The release profile of loaded Orange II molecules at the P-MSN and MSN-TAs samples was studied under the simulated intestinal fluid ( $\mathrm{pH} 7.4)$; the results are summarized in Figure 9a. MSN-TA samples with lower surface positive charge (MSN-TA-1) exhibited a higher initial burst release (53\% of the loaded amount) within $60 \mathrm{~min}$, and a slower release rate in the following $500 \mathrm{~min}(65 \%$ of the loaded amount). This initial burst release may be contributed from Orange II molecules that were adsorbed on the external surface outside of the MSN-TA nanochannels. On the contrary, MSN-TA-4 sample (with highest surface positive charge) showed only the release of $30 \%$ of loaded drugs in the initial $60 \mathrm{~min}$; and then $80 \%$ within $500 \mathrm{~min}$. The P-MSN sample, which was without any TA modification, showed a fast releasing profile within $120 \mathrm{~min}(85 \%)$. In addition, the release profile of MSN-TAs loaded with Orange II molecules in an

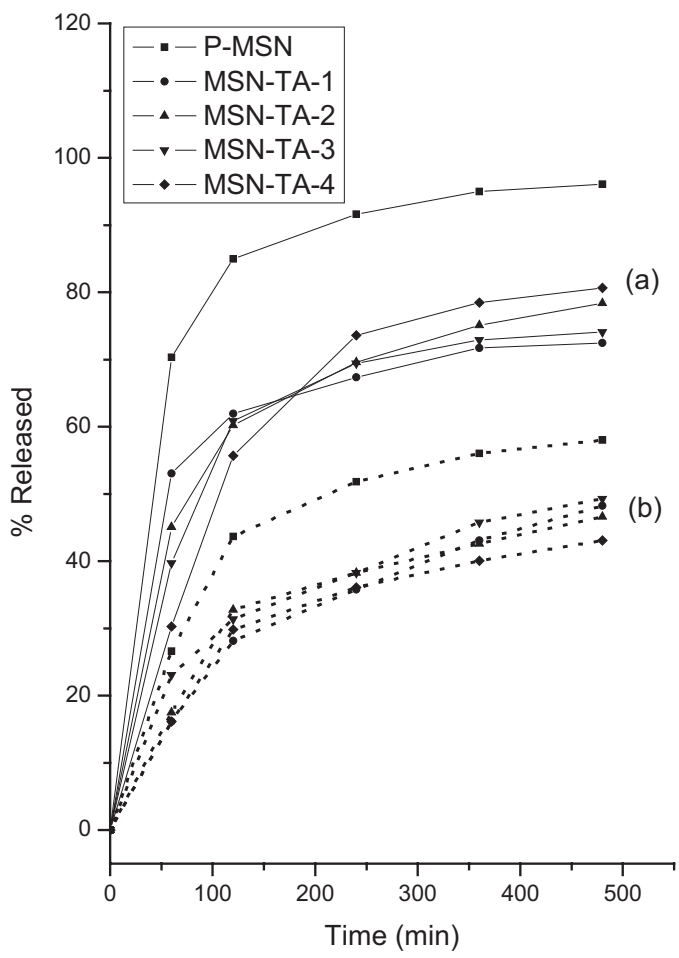

Figure 9. Orange II released at $37^{\circ} \mathrm{C}$ of (a) ringer's (solid line) and (b) $0.1 \mathrm{M} \mathrm{HCl}$ solution (dot line). (घ) P-MSN, (•) MSN-TA-1,

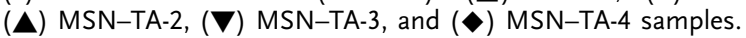

environment similar to gastric fluid ( $\mathrm{pH}$ 1.2) showed insignificant release not only in the initial burst release but also for the following $500 \mathrm{~min}$. The release of Orange II molecules from MSN-TA samples may be dependent on two mechanisms: electrostatic repulsion (Scheme 1c) and ion exchange (Scheme 1d). A large amount of Orange II molecules could be adsorbed in a weak acid environment $\mathrm{pH}$ (Scheme 1a and 1b); they were released rapidly in $\mathrm{pH} 7.4$ solutions. To facilitate the adsorption of negatively charged molecules, the MSN-TA samples were placed in solutions with $\mathrm{pH}$ value maintained in the range of $4-6$, in such condition the unmodified silanol groups were protonated and uncharged and thus did not interfere the electrostatic attraction between the positively charged TA groups and the negatively charged dye/drug molecules (Scheme 1b). At physiological buffer ( $\mathrm{pH}$ around 7.4), the silanol groups ( $\mathrm{Si}-\mathrm{OH})$ in the MSN-TA surface would become deprotonated, and a strong electrostatic repulsion between the negative charges of $\mathrm{MSN}\left(\mathrm{SiO}^{-}\right.$groups) and the negative charge of dye/drug molecules (Scheme 1c) would be generated. Consequently, the $\mathrm{pH}$ value of 7.4 in the physiological buffer promoted the releasing rate of the anionic molecules. In the simulated gastric fluid $(\mathrm{pH} 1.2)$, the unmodified silanol groups in the MSN surface were fully protonated, so the MSN-TA surface predominantly carried positive charges (contributed from the TA groups). Consequently, the electrostatic attraction between the positive charge of TA groups and negative dye/drug molecules in acidic condition caused a decrease in the release rate. The mechanism of slow release of Orange II in the simulated gastric fluid may be from the ion exchange (anionic dye/drug exchanged with $\mathrm{Cl}^{-}$) and diffusion by the concentration gradient (Scheme 1d).

The release profiles of MSN-TAs-sulfasalazine samples in a simulated intestinal fluid ( $\mathrm{pH} 7.4$ ) are shown in Figure 10a. For the MSN-TA-1 sample, the highest initial burst release of 33\% took place within $1 \mathrm{~h}$, and $90 \%$ of the loaded sulfasalazine was slowly released within the following $20 \mathrm{~h}$. MSN-TA-4 sample showed the lowest initial release rate in the initial $1 \mathrm{~h}(10 \%)$, and $57 \%$ was released within $20 \mathrm{~h}$. From the release profiles of Orange II and sulfasalazine, one could effectively regulate the release rate by incorporating different amounts of TA groups inside the framework of MSN. In addition, the release rate of sulfasalazine in neutral $\mathrm{pH}$ was much slower when compared with that of Orange II molecules. A possible reason may be the hydrophobic nature of sulfasalazine molecules. Although the electrostatic repulsion will speed up the release rate of sulfasalazine molecules at a neutral $\mathrm{pH}$, the hydrophilic environment of the releasing medium will prevent the sulfasalazine molecules from diffusing into the medium. Figure $10 \mathrm{~b}$ showed the release profiles of sulfasalazine in a simulated gastric fluid ( $\mathrm{pH}$ 1.2). We observed that the MSN-TA samples were only trace release of sulfasalazine under $\mathrm{pH} 1.2$, even though only $10 \%$ of sulfasalazine release in the $20 \mathrm{~h}$ of release period. Besides, the P-MSN sample loaded with Orange II or sulfasalazine showed a poor protection against the fast release either in $\mathrm{pH} 7.4$ physiological buffer or in 


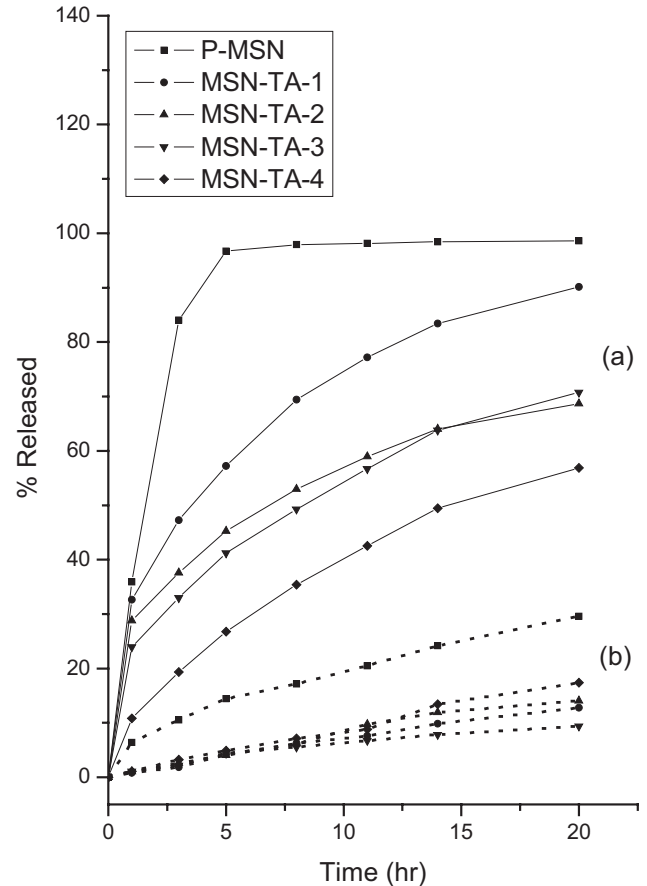

Figure 10. Sulfasalazine released at $37^{\circ} \mathrm{C}$ of (a) Ringer's (solid line) and

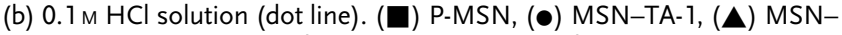
TA-2, ( $\boldsymbol{\nabla})$ MSN-TA-3, and $(\bullet)$ MSN-TA-4 samples.

$\mathrm{pH} 1.2$ of simulated gastric fluid. The drawbacks of P-MSN sample come from the low loading efficiency of the drug molecules (Table 1 and Fig. 6 and 7) and the large leaching of the loading molecules under $\mathrm{pH} 1.2$ of simulated gastric fluid, therefore the TA modified of MSN samples were indeed an ideal carrier for colonic targeted drug-delivery system. Horcajada et al. ${ }^{[12]}$ indicated that the pore size of Si-MCM41 would influence the release rate of the analgesic ibuprofen. Our experiments of nitrogen adsorption-desorption isotherms showed that the surface area and pore size were almost the same in P-MSN and MSN-TA samples (Table 1). Therefore, the release rate of our MSN carriers was predominantly regulated by the surface charges in different $\mathrm{pH}$ values. This system exhibited sustained release property, though $10-20 \%$ of the loading molecules remained in the support for a long period. The residual dye/drug molecules may be occluded in the channels and therefore could not achieve the overall release. The electrostatic attraction between the dye/drug molecules and the MSN-TA surface was stronger than the hydrogen bonding $\left(-\mathrm{NH}_{2}{ }^{8-}{ }_{-}^{\delta+} \mathrm{HOOC}-\right)$ and the weaker ionic attraction $\left(-\mathrm{NH}_{3}{ }^{+}-{ }^{-} \mathrm{OOC}-\right)$. By the hydrophobic effect and electrostatic interaction, a prodrug molecule (sulfasalazine) targeting at colon tissue was protected and adsorbed inside the nanochannels of MSN-TA samples in the simulated gastric fluid, and this formulation of MSN-TA-sulfasalazine complex decreased both side effects and the degradation of prodrug molecules in the stomach and small intestine. To the best of our knowledge, this is the first report on the use of nanosized mesoporous silica to combine the $\mathrm{pH}$-sensitive and prodrug strategies for oral drug delivery. We expect that the combination of these two release mechanisms to be applicable to the colon-specific drug delivery following oral administration. Such delivery system can reduce the non-specific release during transportation and the possible side effects in the stomach and small intestine.

\section{Conclusions}

A pH-responsive controllable drug release system has been designed by incorporating positive charges in the framework of MSN so that anionic molecules can be efficiently adsorbed inside of the nanochannels with minimal release under acidic $\mathrm{pH}$ value. At neutral $\mathrm{pH}$ because of the deprotonation of surface silanol groups, while giving strong electrostatic repulsion, the release rate of the adsorbed drug molecules becomes much increased. The amounts of drug adsorbed and the release rate could be regulated by the control of different TA amounts in the MSN. This controlled-release mechanism takes advantage of the changing $\mathrm{pH}$ value and ionic strength in our physiological buffer. The MSN-TA materials possess many advantages in pharmaceutical applications, including good control of particle size in the $\sim 100 \mathrm{~nm}$ range, large surface areas, high pore volume, high loading of anionic drugs, which leads to good control in the release rate. A series of MSN-TA samples with an average particle size of $100 \mathrm{~nm}$, pore diameter of $2.7 \mathrm{~nm}$, and different surface charges have great potential for utilizing the size-defined nanoparticles for targeted delivery and in vivo diagnostics. The storage capacity of the anionic molecules could be controlled either by varying the TA density in MSN or varying the concentration and $\mathrm{pH}$ value in the adsorption solution. We demonstrated that a single step of solgel process could be used to synthesize a $\mathrm{pH}$-triggered drugrelease system. The nanochannels of MSN-TA samples have the advantage of holding the drug molecules in acidic condition and protecting them from degradation in the stomach. Hence, this kind of the carrier could be designed as oral drug delivery system that improves site specificity and release kinetics to accommodate different therapeutic purposes.

\section{Experimental}

Materials: TEOS, CTAB, Orange II, and ammonium hydroxide $(30 \%)$ were purchased from Acros. Sulfasalazine was obtained from Sigma Chemical Co. $N$-Trimethoxysilylpropyl- $N, N, N$-trimethylammonium chloride (50\% in methanol) was obtained from Gelest. Ringer's solution has a composition very similar to human plasma $(\mathrm{NaCl}$, $8.60 \mathrm{mg} ; \mathrm{KCl}, 0.3 \mathrm{mg} ; \mathrm{CaCl}_{2}, 0.33 \mathrm{mg}$ every $1 \mathrm{~mL}$ of $\mathrm{H}_{2} \mathrm{O}$ ).

Preparation of MSN-TA Samples: The MSN - TA samples with a hexagonal well-ordered pore structure were synthesized under a low concentration of TEOS, surfactant, and a base catalyst $\left(\mathrm{NH}_{4} \mathrm{OH}\right)$ in a two-step preparation [26]. The sol-gel process for the co-condensation of TEOS and $N$-trimethoxysilylpropyl- $N, N, N$-trimethylammonium chloride to synthesize MSN-TA samples was as follows. First, $0.1 \mathrm{~g}$ of CTAB was dissolved in $50 \mathrm{~g}$ of $0.51 \mathrm{M} \mathrm{NH}_{4} \mathrm{OH}$ at $50^{\circ} \mathrm{C}$, and $0.8 \mathrm{~mL}$ of 
$0.2 \mathrm{M}$ dilute TEOS (in ethanol) was added with vigorous stirring. After the solution was stirred for $5 \mathrm{~h}, 0.8 \mathrm{~mL}$ of $2 \%$ (MSN-TA-1), $5 \%$ (-TA-2), 8\% (-TA-3), and 12\% (-TA-4) (v/v) of $N$-trimethoxysilylpropyl- $N, N, N$-trimethylammonium chloride (in ethanol) and $0.8 \mathrm{~mL}$ of $1.0 \mathrm{~m}$ TEOS were added with vigorous stirring for another $1 \mathrm{~h}$. The solution was then aged at $50^{\circ} \mathrm{C}$ for $24 \mathrm{~h}$. Samples were collected by centrifuging at $12000 \mathrm{rpm}$ for $20 \mathrm{~min}$, washed, and redispersed with deionized water and ethanol several times. The solid products were obtained by centrifuge. The surfactant templates were removed by extraction in acidic ethanol (about $0.17 \mathrm{~g}$ of $\mathrm{HCl}$ in $9 \mathrm{~mL}$ of ethanol at $65^{\circ} \mathrm{C}$ for $24 \mathrm{~h}$ ).

Preparation of the Orange II Loaded MSN-TA Samples: The different concentrations $(0.25,0.75,1.25,1.75,2.25,2.75 \mathrm{~mm})$ of Orange II were prepared by the dissolution of the solid Orange II in $\mathrm{H}_{2} \mathrm{O}$. The $\mathrm{pH}$ value was adjusted to 6.8 by adding a trace of $\mathrm{NaOH}$ or $\mathrm{HCl}$ solution. About $15 \mathrm{mg}$ of MSN-TA sample was added to the $2.5 \mathrm{~mL}$ of above solution and stirred at $30^{\circ} \mathrm{C}$ for $2 \mathrm{~h}$. The particles were then washed with deionized water, centrifuging at $12000 \mathrm{rpm}$ for $20 \mathrm{~min}$ Residual solution was diluted 50 times with deionized water and analyzed with a UV-Vis spectrometer. Orange II adsorbed in the nanoparticles was determined by measuring the decrease of absorption peak at $480 \mathrm{~nm}$. Calibration experiments were done separately before each set of measurements with Orange II of different concentrations. The loading percentage of Orange II in MSN-TA-4 was near $5.9 \% \mathrm{w} / \mathrm{w}$.

Preparation of the Sulfasalazine-Loaded MSN-TA Samples: We prepared a saturated sulfasalazine aqueous solution as follows. First, we dissolved $0.5 \mathrm{~g}$ of sulfasalazine in $1 \mathrm{~L}$ of $\mathrm{H}_{2} \mathrm{O}$ under stirring for $6 \mathrm{~h}$. The residual solids were filtered through a $0.45 \mu \mathrm{m}$ cellulose acetate membrane. The saturated sulfasalazine in aqueous solution was near $75 \mu \mathrm{M}$ and $\mathrm{pH}$ 5.4. Second, we adsorbed sulfasalazine in MSN-TA samples by the addition $10 \mathrm{mg}$ of MSN-TA samples in $10 \mathrm{~mL}$ of above saturated solution. The mixture was stirred at $800 \mathrm{rpm}$ for $4 \mathrm{~h}$. The particles were then washed with deionized water and centrifuged at $12000 \mathrm{rpm}$ for $20 \mathrm{~min}$. The residual solution was analyzed with a UVVis spectrometer. Sulfasalazine adsorbed in the nanoparticles was determined by measuring the decrease of absorption peak at $360 \mathrm{~nm}$. The loading percentage of sulfasalazine in MSN-TA-4 was near $1.7 \%$.

Preparation of the Sulfasalazine-Loaded MSN-TA Samples in DMSO Solution: To increase the loading percentage, we adsorbed sulfasalazine in DMSO by the addition of $20 \mathrm{mg}$ of MSN-TA samples in $1.5 \mathrm{~mL}(10 \mathrm{~mm})$ of sulfasalazine. The mixture was stirred at $800 \mathrm{rpm}$ for $4 \mathrm{~h}$. The particles were then washed with DMSO and centrifuged at $12000 \mathrm{rpm}$ for $20 \mathrm{~min}$. Residual solution was analyzed with a UV-Vis spectrometer. The loading percentage of sulfasalazine in MSN-TA-4 was near $4.1 \%$.

In Vitro Release Studied: In vitro release experiments were performed in simulated gastric fluid $(\mathrm{pH} 1.2$ of $0.1 \mathrm{M} \mathrm{HCl})$ and intestinal fluid ( $\mathrm{pH} 7.4$ of ringer's solution) to mimic Orange II and sulfasalazine release in the stomach and colon. The experimental condition was as follows. First, $5 \mathrm{~mL}$ of simulated fluid was added to $20 \mathrm{mg}$ of dye- or drug-adsorbed MSN-TA samples and kept at $37^{\circ} \mathrm{C}$ while being stirred at $100 \mathrm{rpm}$. The release medium was removed for analysis at given time intervals by centrifuging at $12000 \mathrm{rpm}$ for $20 \mathrm{~min}$. The solids residual were added the same volume of fresh simulated fluid. The released percentage of the dye and drug molecules in the solution phase was determined by measuring the concentration periodically.

Characterization: The surface area, pore size, and pore volume were determined by $\mathrm{N}_{2}$ adsorption-desorption isotherms obtained at $77 \mathrm{~K}$ on a Micrometric ASAP 2010 apparatus. The sample was outgassed at $10^{-3}$ Torr and $120^{\circ} \mathrm{C}$ for about $3 \mathrm{~h}$ prior to the adsorption experiment. The pore size distribution curves were obtained from the analysis of the adsorption portion of the isotherms using the $\mathrm{BJH}$ (Barrett-Joyner-Halenda) method. UV-Vis spectra were taken on a Hitachi U-3010 spectrophotometer. The spectra were separately collected in the intensity of 480 and $360 \mathrm{~nm}$ wavelength for Orange II and sulfasalazine against a standard. FTIR spectra were recorded on a Nicolet 550 spectrometer with a $\mathrm{KBr}$ pellet. About $1 \mathrm{mg}$ of sample was mixed with $300 \mathrm{mg}$ of dried $\mathrm{KBr}$ and then pressed. The structures of MSN-TA samples were analyzed by powder X-ray diffraction (XRD) with a Scintag $\mathrm{X} 1$ diffractometer using copper $\mathrm{K} \alpha$ radiation at $\lambda=0.154 \mathrm{~nm}$. The $\zeta$-potentials of pure form MSN (P-MSN) and MSNTA samples were measured in a Malvern Nano-HT Zetasizer. Zeta potential distribution was obtained by the average of ten measurements. The samples were prepared in the concentration of $2 \mathrm{mg}$ in $1 \mathrm{~mL}$ of $\mathrm{ddH}_{2} \mathrm{O}$. Different $\mathrm{pH}$ values were adjusted by the addition of $0.02 \mathrm{M}$ $\mathrm{HCl}$ or $\mathrm{NaOH}$. Before measurement, each sample was ultrasonicated for $5 \mathrm{~min}$ to prevent any aggregation.

Received: April 17, 2008 Revised: June 25, 2008 Published online: October 7, 2008

[1] G. Van den Mooter, R. Kinget, Drug Deliv. 1995, 2, 81.

[2] G. T. MacFarlane, J. H. Cummings, S. MacFarlane, G. R. Gibson, $J$. Appl. Bacteriol. 1989, 67, 521.

[3] C. T. Kresge, M. E. Leonowicz, W. J. Roth, J. C. Vartuli, J. S. Beck, Nature 1992, 359, 710.

[4] a) P. Van Der Voort, M. Baltes, E. F. Vansant, J. Phys. Chem. B 1999 , 103, 10102. b) M. Baltes, K. Cassiers, P. Van Der Voort, B. M. Weckhuysen, R. A. Schoonheydt, E. F. Vansant, J. Catal. 2001, 197, 160. c) D. E. De Vos, M. Dams, B. F. Sels, P. A. Jacobs, Chem. Rev. 2002, 102, 3615.

[5] a) A. Vinu, M. Miyahara, K. Ariga, J. Nanosci. Nanotechnol. 2006, 6, 1510. b) A. Vinu, M. Miyahara, K. Z. Hossain, M. Takahashi, V. V. Balasubramanian, T. Mori, K. Ariga, J. Nanosci. Nanotechnol. 2007, 7, 828. c) M. Hartmann, Chem. Mater. 2005, 17, 4577. d) M. A. ValletRegi, L. Ruiz-Gonzalez, I. Izquierdo-Barba, J. M. Gonzalez-Calbet, $J$. Mater. Chem. 2006, 16, 26

[6] a) K. A. Fisher, K. D. Huddersman, M. J. Taylor, Chem. Eur. J. 2003, 9, 5873. b) G. Cavallaro, P. Pierro, F. S. Palumbo, F. Testa, L. Pasqua, R. Aiello, Drug Deliv. 2004, 11, 41. c) Q. L. Tang, Y. Xu, D. Wu, Y. H. Sun, J. Solid State Chem. 2006, 179, 1513. d) W. Zeng, X. F. Qian, J. Yin, Z. K. Zhu, Mater, Chem. Phys. 2006, 97, 437. e) N. E. Botterhuis, Q. Y. Sun, P. C. M. M. Magusin, R. A. van Santen, N. A. J. M. Sommerdijk, Chem. Eur. J. 2006, 12, 1448. f) C. Tourne-Peteilh, D. A. Lerner, C. Charnay, L. Nicole, S. Begu, J. M. Devoisselle, Chemphyschem 2003, 4, 281. g) J. Salonen, L. Laitinen, A. M. Kaukonen, J. Tuura, M. Bjorkqvist, T. Heikkila, K. Vaha-Heikkila, J. Hirvonen, V. P. Lehto, J. Control. Release 2005, 108, 362. h) M. Arruebo, M. Galan, N. Navascues, C. Tellez, C. Marquina, M. R. Ibarra, J. Santamaria, Chem. Mater. 2006, 18, 1911. i) C. Charnay, S. Begu, C. TournePeteilh, L. Nicole, D. A. Lerner, J. M. Devoisselle, Eur, J. Pharm. Biopharm. 2004, 57, 533. j) J. Andersson, J. Rosenholm, S. Areva, M. Linden, Chem. Mater. 2004, 16, 4160.

[7] a) I. I. Slowing, B. G. Trewyn, S. Giri, V. S. Y. Lin, Adv. Funct. Mater. 2007, 17, 1225. b) I. Slowing, B. G. Trewyn, V. S. Y. Lin, J. Am. Chem. Soc. 2006, 128, 14792. c) B. G. Trewyn, C. M. Whitman, V. S. Y. Lin, Nano Lett. 2004, 4, 2139. d) C. Barbe, J. Bartlett, L. G. Kong, K. Finnie, H. Q. Lin, M. Larkin, S. Calleja, A. Bush, G. Calleja, Adv. Mater. 2004 16, 1959. e) D. M. Huang, Y. Hung, B. S. Ko, S. C. Hsu, W. H. Chen, C. L. Chien, C. P. Tsai, C. T. Kuo, J. C. Kang, C. S. Yang, C. Y. Mou, Y. C. Chen, FASEB J. 2005, 19, 2014

[8] J. Lu, M. Liong, J. I. Zink, F. Tamanoi, Small 2007, 8, 1341

[9] J. Gu, W. Fan, A. Shimojima, T. Okubo, Small 2007, 3, 1740.

[10] A. Vinu, K. Z. Hossain, K. Ariga, J. Nanosci. Nanotechnol. 2005, 5, 347.

[11] a) M. Vallet-Regi, A. Ramila, R. P. del Real, J. Perez-Pariente, Chem. Mater. 2001, 13, 308. b) A. Ramila, B. Munoz, J. Perez-Pariente, M. Vallet-Regi, J. Sol-Gel Sci. Technol. 2003, 26, 1199. c) B. Munoz, A. 
Ramila, J. Perez-Pariente, I. Diaz, M. Vallet-Regi, Chem. Mater. 2003, 15, 500. d) A. L. Doadrio, E. M. B. Sousa, J. C. Doadrio, J. P. Pariente, I. Izquierdo-Barba, M. J. Vallet-Regi, Control. Release 2004, 97, 125. e) I. Izquierdo-Barba, A. Martinez, A. L. Doadrio, J. Perez-Pariente, M. Vallet-Regi, Eur. J. Pharm. Sci. 2005, 26, 365. f) F. Balas, M. Manzano, P. Horcajada, M. Vallet-Regi, J. Am. Chem. Soc. 2006, 128, 8116. g) F. Y. Qu, G. S. Zhu, S. Y. Huang, S. G. Li, S. L. Qiu, Chemphyschem 2006, 7, 400. h) F. Y. Qu, G. S. Zhu, S. Y. Huang, S. G. Li, J. Y. Sun, D. L. Zhang, S. L. Qiu, Microporous Mesoporous Mater. 2006, 92, 1. i) S. W. Song, K. Hidajat, S. Kawi, Langmuir 2005, 21, 9568. j) Q. L. Tang, Y. Xu, D. Wu, Y. H. Sun, J. Wang, J. Xu, F. Deng, J. Control. Release 2006, 114, 41. k) C. Tourne-Peteilh, D. Brunel, S. Begu, B. Chiche, F. Fajula, D. A. Lerner, J. M. Devoisselle, New J. Chem. 2003, 27, 1415.

[12] P. Horcajada, A. Ramila, J. Perez-Pariente, M. Vallet-Regi, Microporous Mesoporous Mater. 2004, 68, 105.

[13] Y. J. Han, G. D. Stucky, A. Butler, J. Am. Chem. Soc. 1999, 121, 9897.

[14] a) Y. F. Zhu, J. L. Shi, Y. S. Li, H. R. Chen, W. H. Shen, X. P. Dong, Microporous Mesoporous Mater. 2005, 85, 75. b) L. X. Wen, Z. Z. Li, H. K. Zou, A. Q. Liu, J. F. Chen, Pest. Manag. Sci. 2005, 61, 583. c) Z. Z. Li, S. A. Xu, L. X. Wen, F. Liu, A. Q. Liu, Q. Wang, H. Y. Sun, W. Yu, J. F. Chen, J. Control. Release 2006, 111, 81. d) Y. F. Zhu, J. L. Shi, W. H. Shen, X. P. Dong, J. W. Feng, M. L. Ruan, Y. S. Li, Angew. Chem. Int. Ed. 2005, 44, 5083. e) J. F. Chen, H. M. Ding, J. X. Wang, L. Shao, Biomaterials 2004, 25, 723.

[15] a) D. R. Radu, C. Y. Lai, K. Jeftinija, E. W. Rowe, S. Jeftinija, V. S. Y. Lin, J. Am, Chem, Soc, 2004, 126, 13216. b) N. K. Mal, M. Fujiwara, Y. Tanaka, T. Taguchi, M. Matsukata, Chem. Mater. 2003, 15, 3385.
[16] a) S. Giri, B. G. Trewyn, M. P. Stellmaker, V. S. Y. Lin, Angew. Chem. Int. Ed. 2005, 44, 5038. b) J. A. Gruenhagen, C. Y. Lai, D. R. Radu, V. S. Y. Lin, E. S. Yeung, Appl. Spectrosc. 2005, 59, 424. c) C. Y. Lai, B. G. Trewyn, D. M. Jeftinija, K. Jeftinija, S. Xu, S. Jeftinija, V. S. Y. Lin, J. Am. Chem. Soc. 2003, 125, 4451.

[17] Q. Yang, S. H. Wang, P. W. Fan, L. F. Wang, Y. Di, K. F. Lin, F. S. Xiao, Chem. Mater. 2005, 17, 5999.

[18] J. S. Beck, J. C. Vartuli, W. J. Roth, M. E. Leonowicz, C. T. Kresge, K. D. Schmitt, C. T. W. Chu, D. H. Olson, E. W. Sheppard, S. B. Mccullen, J. B. Higgins, J. L. Schlenker, J. Am. Chem. Soc. 1992, 114, 10834.

[19] C. H. Lee, S. T. Wong, T. S. Lin, C. Y. Mou, J. Phys. Chem. B. 2005, 109, 775.

[20] A. Gazanica, M. E. Sangali, M. Giordano, Eur. J. Pharm. Biopharm. 1994, 40, 246.

[21] a) E. Touitou, A. Rubinstein, Int. J. Pharm. 1986, 30, 95. b) R. Peeters, R. Kinget, Int. J. Pharm. 1993, 94, 125.

[22] a) V. R. Sinha, R. Kumria, Pharm. Res. 2001, 18, 557. b) R. Wiwattanapatapee, L. Lomlim, K. Saramunee, J. Control. Release 2003, 88, 1. c) S. Sakuma, Z. R. Lu, P. Kopecková, J. Kopecek, J. Control. Release 2001, 75, 365. d) Y. J. Jung, J. S. Lee, Y. M. Kim, J. Pharm. Sci. 2000, 89, 594.

[23] N. Rouge, P. Buri, E. Doelker, Int. J. Pharm. 1996, 136, 117.

[24] a) S. L. Gorbach, Gastroenterology 1971, 60, 1110. b) A. Rubinstein, Biopharm. Drug Dispos. 1990, 11, 465. c) R. R. Scheline, Pharmacol. Rev. 1973, 24, 451.

[25] M. K. Chourasia, S. K. Jain, J. Pharm. Pharm. Sci. 2003, 6, 33.

[26] Y. S. Lin, C. P. Tsai, H. Y. Huang, C. T. Kuo, Y. Hung, D. M. Huang, Y. C. Chen, C. Y. Mou, Chem. Mater. 2005, 17, 4570. 